\title{
Peripecia del Mar y de la Costa en Abraham Valdelomar
}

\author{
Valdelomar: Valle del Mar.
}

$\mathrm{F}^{\mathrm{N}}$ el tinglado de su producción literaria estuvieron frecuentemente dialogando el litoral y el océano. Por sobre el azul de cielo y agua se abrió el surco verde del valle costeño, integrado por la aldea y el área de cultivo que, encerrada en la inmensidad del desierto blanquecino de arena, viene a morir a la playa. Atrás de la mirada del espectador quedó la cordillera. Sólo llegaron de ella los matices reflejados en la costa, donde se realizaba - centralmente- el drama que Valdelomar pudo advertir, y al que supo dar vida estética. Los Andes significaron en él, haz de luz proyectada hacia el escenario, pero no personaje, ni decorado.

Los motivos de nuestra costa y de nuestro mar habían sido, hasta entonces, esporádicamente tratados en la literatura. Los viejos mitos yungas trazaron en simples cuadros la desnudez del litoral y la épica hazaña de sus primitivos pobladores. Viracocha, emergiendo de las olas, y Pachacámac, telúrico personaje de arena y roca, hundiendo su figura en los médanos que forman abanicos a la vera del agua salada, caracterizan ya la tragedia que tiene un cíclico desarrollo. Alrededor de ellos están las otras figuras. El semidiós Con, incorpóreo y extraño ser, que "abajó las montañas", que avanzaban erguidas y altas hacia el mar, para hacer la delgada serpentina costeña, donde germinaron los primitivos hombres en la tierra hinchada. Los riachuelos, que han de correr atemorizados por la superficie perlada que habla de hambre y de soledad. Crecerán, más tarde, las raíces, las hierbas y los frutos de los sanguinolentos miembros desgajados del hijo concebido por Viracocha y muerto por 
Pachacámac, en este combate que constituye la gran fase inicial de nuestra epopeya. Morirán -a la recíproca- los gigantes que creara el dios de arena y serán convertidos en peñoles e islotes, huacas y cerros, como manifestación del poderío del dios del mar. En estos elementos de la preliteratura peruana hay una interpretación cosmogónica y un delinearse de los.motivos constitutivos de la zona yunga. Curacas, caciques y mitayos irán forjando luego el resto de la historia precolombina, donde se levanta fantasioso el reino de Naylamp o el del viejo Tumbe con las románticas aventuras de Guayanay. Mates, golondrinas, pescados, piraguas, arena, agua verdiazul y un horizonte donde los dioses danzan a la caída de la tarde sobre el cielo escarlata. El dios Viracocha se aleja, después, del litoral y se hace personaje serrano, agigantando su silueta en los ocasos del Titicaca; por él se crean las "pacarinas", de donde sale todo lo que vida tiene y encierra, y por él los hombres, nacidos —en esta nueva interpretación mítica - de la piedra andina, corren hacia el ombligo del mundo para forjar el Imperio de los Ayar. El mito lleva a los descendientes de Guayanay a las profundas quebradas de la sierra y a los Punas de dilatado horizonte, para que bajo el nombre Capitán de Manco escriban la página central del pasado pertuano. La costa había perdido su primacía.

Las crónicas de la conquista están hechas de acción y para la acción; todo lo que la naturaleza encierra de drama permanente no fué sino mero marco descriptivo. Nuestra costa fué pintada como angosta faja de tierras estériles en su mayoría, donde apenas cae una llovizna y donde el mar calmo se encrespa en contados lugares para barrer la superficie de las playas norteñas o para estallar en furia contra las rocas desafiantes del sur. Los poemas de pirațas vinieron a traer nuevamente al mar al campo literario. Pero su papel fué descolorido e intrascendente. Eran los corsarios atrevidos y los esforzados defensores de las plazas virreinales, los héroes de las acciones cantadas; y el litoral y el océano: escenarios, mas no personajes; decoración, pero nunca motivo central, ni figura dialogable. Aurelio Miró Quesada en su ensayo "El mar: personaje peruano", ha hecho una vívida descripción de los episodios marinos relacionados con nuestro país y la significación que tuvieron en el desenvolvimiento de nuestra historia. Acontecer de hechos sobre el mar, pero no acerca del mar. Acaso si en el poema del Conde 
de la Granja, al par que se intenta presentar el valle costeño de Lima se proyecta una acción del mar en las aventuras de los corsarios; novedad entre las amaneradas y densas estrofas del autor de "La vida de Santa Rosa". Pero ni en él, ni después, se consigue dar carácter al litoral o al mar, hasta que Melgar encuentra ante su vista las notas de inmensidad y abandono, que son eco de su alejamiento de Silvia y de su tormentoso dolor de adolescente. La lírica había murmurado, en cambio, lamentos cordilleranos en los centros culturales mestizos, superviviendo el símbolo de la palomita y el nido, en los cantares quechuas. Tras Melgar, los románticos giran alrededor de las playas y el mar, soñando en "Occidente"; pero miran en él la reproducción de sus angustias, sus fingidos dolores; y la luna presagia sobre el tendido ponto la hora de la desesperación y el trágico desenlace de alguna historia de amor imposible. La playa y el mar son, entonces, escenarios de las quimeras de poetas "sensibles" que se recrean en inventar pasiones atormentadas, imágenes lánguidas o tristes relatos, donde los seres humanos se asemejan generalmente a "frágiles naves al piẻlago lanzadas". A veces transitan por él tiernas baladas que recuerdan a Goethe, a Víctor Hugo. En cierta ocasión la tragedia hizo efectivamente carne y realidad en "Los yermos del mar" sobre un poeta romántico, $\mathrm{Ma}$ nuel Nicolás Corpancho, y Salaverry dijo entonces:

Fueron de llamas y salobre espuma

los pliegues de tu sábana mortuoria...;

y más adelante:

Qué importa tu naufragio aquí en la tierra,

si flotante en un verso va tu nombre

de una ola en otra hasta la edad futura...

Althaus encuentra "camino del cielo la dormida' llanura del mar". Palma ve reflejarse en él la congoja juvenil que lo acosa. Es Juan de Arona quien lo describe -entre los románticos del Perúcon más precisas notas; lo mira frente a él, no superpuesto a él, ni parte de él; sino ante la vista, en su integridad física, en su propio desenvolverse. Las olas ruedan mansas y dejan sus altos copos de espuma nevada sobre la playa y se retiran y vuelven en majestuoso desarrollo. Al final la nota emotiva deja abierto el camino de la poesía sensible: 
Que era la hora aquella

en que el mar se serena y se reviste

de un azul más profundo y de un aspecto

más solemne y más triste...

Para nuestra costa tiene también Juan de Arona aciertos descriptivos en sus conocidos "Cuadros y episodios peruanos". Los algodonales de Cañete; la bruma de Lima; los contornos de los arenales; el desteñido verde, polvoriento, de nuestros valles:

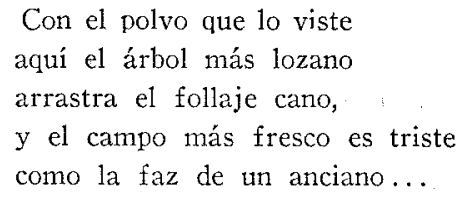

Sus poemas "La costa" y "La costa peruana" presentan, con incisivas notas críticas, los pormenores del panorama que "duerme amodorrado al pie del mar". Asoman los médanos, las haciendas costeras, los cantos de "los vigilantes gallos"; los pequeños oasis cultivados en medio de las "arenas, el desierto y los barrancos" que expresa: "del olvido de Dios dan triste muestra". Y añade que nuestra costa es "Africa sin camellos, ni palmas", sin grandes "montes, ríos, árboles ni lagos".

Pobreza, desnudez, contornos vagos.

- Y un bello clima, y una dulce calma que dan la muerte entre embriaguez y halagos...

Mas también manifiesta que él cantará "con metro diferente" la "verde alfombra del maíz naciente", el "vago y apacible colorido" del "yucal dormido", las "lucientes hojas del camotal y la amarilla flor del rústico zapallo". La obra de Pedro Paz Soldán Unanue es de gran interés para un estudio de nuestro litoral. Pero su poesía es descriptiva y hecha a la medicla del ángulo virgiliano y no hay una interpretación o una expresión de trascenđencia, más allá de lo meramente palpable o visible. En tanto crecían un sentimiento y una estética andinos y el elemento aborigen que apareció ya en las páginas precursoras del "Padre Horán", se hace prototipo de novela. La cultura peruana se ha ido galvanizando con la mirada puesta en el sector serrano. Con acierto pasajero o con deficiente 
perspectiva, el escritor sólo busca -en cierto momento- las raíces nacionales dentro de las altas murallas de granito y tiene la espalda al oeste.

José Santos Chocano en su afán de conseguir una poesía que conjugara con la realidad histórico-geográfica, cantó los Andes, los cóndores, las punas, por un lado; y las orquídeas, las magnolias, la selva enmarañada y trágica, los grandes ríos, por otro. La costa estuvo centralizada en esa poesía entre los linderos de Lima con visiones virreinales, gobernantes galantes, tapadas, evocaciones de la vida colonial. Todo esto elentro de su reconocida retórica poética. Crecían los fermentos de una vuelta literaria a los motivos que iniciara el grupo radical y positivista y el indigenismo hizo cuerpo por sobre la posición académica del 900 .

Es en Abraham Valdelomar donde vibraron por sí mismos y con notas peculiares el mar y la costa peruanas. Fué ya interpretación y exégesis, al mismo tiempo. Su obra no quedó, así, en el campo del costumbrismo, de la repetición folklórica, de la acentuación del carácter criollo o vernacular. El océano y el litoral fueron personajes literarios hechos al diapasón estético o sea en persecución de la belleza, trasrealizando lo visto y lo escuchado con indudable genialidad poética. Ya decía Ricardo Vegas García: "Lo que en cualquier criollo es alegre zumba y gracejo vulgar, en Valdelomar era fina ironía, humorismo elevado y sano."

Valdelomar no reflejó exactamente la realidad, sino que precisamente su valor estriba en que extrajo de aquélla, apariencias significativas; exprimió los detalles para hacer alquitarada exprẹsión. El doctor Mariano Ibérico Rodríguez en su estudio sobre "La transrealidad del objeto poético" ha hecho valiosas sugerencias sobre el tema en general. "La poesía - dice- al par que trasciende la inmediata y corpórea realidad del mundo circundante nos entrega un mensaje de profundidad y encierra un sentido de misteriosa identificación del alma con las fuerzas creadoras de la vida y con la oscura fatalidad del destino." Y Valdelomar, eminentemente poético, extrajo de la realidad lo que en ella encontró de belleza, haciendo paréntesis de lo que no significaba nada para su tabulación de valores estéticos. Por ello, el mar y el litoral fueron estímulos que convertidos en sueños, en visiones de niños, en amorosas escenas bucólicas, en motivos de melancólico recuerdo, dieron con la nota 
crepuscular de su estilo, páginas de delectación artística. Ė mero dato, la pintura costumbrista, no tuvieron cabida en la prosa, ni. en la poesía de Valdeiomar. Degustado el objeto poético se convirtió en valor artístico en sí mismo, ajeno a toda referencia exclusivamente localista, y con trascendente contenido universal. Volviendo nuevamente al citado ensayo del doctor Ibérico nos encontramos con el siguiente párrafo que viene precisamente al caso:

"Hay diversos planos de apariencia, planos que se suceden desde el mero contacto sensible - auditivo, visual - con el objeto poético, hasta el osçuro fundamento ontológico de la aparición. La estructura de colores o sonidos que es en sí misma una imagen, evoca otra imagen -que llamaremos significada- la cual despierta acaso una nueva apariencia, y así en número indeterminado hasta el fondo primitivo e inefable. Es como si asistiéramos a una serie de refracciones de la apariencia a través de zonas cada vez más profundas del alma, o como si proyectáramos el objeto poético transfigurándolo en término de una creciente lejanía y significación."

Si recogemos el mar de "El Hipocampo de Oro" o de "Los ojos de Judas" el sauce solitario, comparado en su insignificancia con la vida de un hombre cualquiera de la aldea; las frutas de las chacras que lindan con la arena o que avanzan hacia la ribera; el gallo heroico; los motivos costeños que se manifiestan en "Yerba santa", con cantos de mar y playa, o entre los nombres dulces de "Verdolaga", apreciaremos que son recogidos -dentro de un método estético - para expresión de lo fundamental: trasunto de sentimiento panteísta, aparición del destino o logro de una acabada forma artística que se convierte en fin en sí mismo. El mar y la costa son dos personajes que bullen palpitantes, que dialogan entre nosotros en un mundo que es mitad realidad y mitad sueño, delineando entre formalidades un trascendente mensaje estético. Luis Fabio Xammar, quien ha dado una certera fisonomía y un perspicaz estudio de Valdelomar, dice refiriéndose a "El Caballero Carmelo", por ejemplo: "Este célebre gallo no es sino un alegre pretexto para hacernos partícipes de hondísimas vivencias y de una dulzura cósmica por la existencia..." Pero, al par, el tipo se "alza enhiesto e incomparable", en plena realidad de personaje cumplido.

Ya se ha dicho que Valdelomar estaba ajeno a todo pintoresquismo. En su ensayo "Belmonte, el trágico" nos ha de mostrar cómo 
concibe la literatura, que no debe obtener el fácil acomodo de la vulgaridad. El éxito acompaña a los mediocres, sostiene, pero la posteridad se encarga de destruirlos porque de ellos no queda "una frase, una idea, una observación sobre nada". "E1 mediocre, sobre un ritmo musical, barato y fácil y por ello universal, ha engarzado ideas baratas, fáciles y universales", afirma, dentro de las consideraciones estéticas que sirven como introito al ensayo citado. En ellas manifiesta una teoría sobre "el ritmo" de la obra literaria. De una previa división en tres etapas rítmicas, se desprende que hay uno natural, en que el universo se nos presenta tal cual es, con pureza de líneas, sin emoción ulterior; luego, un ritmo inteligente en que la naturaleza es interpretada por el autor, producto de la razón, búsqueda de imágenes consecuentes, ausencia de la aparición inicial: el ropaje cubre los objetos; y por último, el ritmo supremo, en que la naturaleza se nos presenta en toda su verdad pavorosa: "es la naturaleza que piensa - dice Valdelomar-, es la misma Venus de Milo con las floridas galas de la primavera y con la trágica belleza de la cabeza de Medusa". Vendría a ser esta tercera etapa, una conjunción de las dos primeras manifestaciones, integración de valores. De ahí que Valdelomar se esforzara en mostrarnos la verdad que aparecía tras un crepúsculo al pie del mar, lo que expresaban los guarangos abandonados en los arenales, to que hay de humano - y de humano a cósmico- en un gallo de pelea o en un caballito de mar, nimbado con el oro de la leyenda y ávido de la copa de sangre, de los ojos y del azahar del durazno, que le ofrece año a año la poesía del hombre, para conseguir aquello que en lenguaje platónico se escribiría Amor, con mayúscula.

Tennyson dijo:

Golpea, golpea, golpea

en las frías piedras grises, ioh mar!...

Y Valéry, un siglo desptués:

Sí, mar, gran mar de delirios dotado, piel de pantera y clámide horadada por millares de imágenes del sol, ebria en tu carne azul, hidra absoluta que te muerdes la cola refulgente en un tumulto análogo al silencio... 
En el primero de los poetas nombrados, el mar traía asociaciones místicas y se veía sobre él caminar las naves hacia el definitivo puerto, mientras las notas crepusculares indicaban que había pasado un día más en el desfile de lo finito a lo infinito. En el segundo, el mar es un motivo de delectación. "El cementerio marino" viene a ser una fuente sugerente de imágenes donde se muestran los poliedros del mar con visión y manera poéticas. E1 océano vive en Tennyson para darnos la idea de un mundo que marcha hacia el más allá, a la bahía inmensa y sombreada al pie de la colina. En Valéry es la recreación de lo presente; el mar resulta eterno y trascendente en sí mismo, sin comparación o referencia. Valdelomar tuvo también presente el paisaje y la palabra del mar. La playa significó su punto de observación y cada reventar de ola o cada ocaso era un motivo de búsqueda estética relacionado con la vida que transcurría en las riberas; ya entre las casas de la aldea - una, cualquiera-; ya entre los botes de los pescadores que echan sus velas al alba; o en las arenas donde varan los cadáveres, los huesos de ballena y las hierbas marinas y adonde sale a conversar la legendaria figura del "Hipocampo de Oro". El mar vivía plenamente y el escritor transcribía los mensajes de la naturaleza en su desgarrante autenticidad. Las horas no marcan el tiempo sino la angustia de las cosas que son estímulo o reflejo de las preocupaciones del hombre. Al oído de éste le hablan la costa y el océano.

"Yo he nacido en el campo y he nacido en abril." La partida de bautizo de Abraham Valdelomar extendida por el cura párroco de la Iglesia Matriz de San Jerónimo de Ica -que reprodujera Xammar en " 3 "-, indica su nacimiento autumnal en esa ciudad; y según lo manifestado en ella, el 16 de abril y no el 27 , como se ha generalizado.

Muy niño estaba ya en Pisco, sobre el litoral.

Mi infancia que fué dulce, serena, triste y sola se deslizó en la paz de una aldea lejana, entre el manso rumor con que muere una ola y el tañer doloroso de una vieja campana...

Desde entonces, afirma que el mar "le dió la nota de su melancolía" y que cada "mañana azul" llegaba hasta su casa el "soplo denso y perfumađo" del océano. "Lo que él me dijera aún en mi alma persiste..." 
Atrás le hablaba el retazo de campo y la monótona vida del villorrio. Hay un tono de ternura hogareña y de paz soleada de pequeña ciudad, que anticipa aquellos melancólicos y sabrosos versos de los primeros años de Vallejo. E1 sitio vacío del hermano lejano y la madre que ve el lugar del ausente y se pone a llorar. Sólo que en Valdelomar asoma su morbidez la arena que las olas azotan... "La paraca despeina su verde caballera..." y "junto al pescador gira la alba gaviota". En Vallejo hay el color vívido de las serranías y el hombre alza los ojos a la altura; en la costa la vista se torna gris hacia el horizonte. Valdelomar recorre los elementos que rodean su vida familar: en "el ñorbo del jardín" hacían "nido los gorriones"; y la "higuerilla", que "se balanceaba con la brisa marina", tendia sus hojas que él y sus hermanos rozaban "cariñosamente"... "Las palomas, con sus alas de abanico, eran la nota blanca..." En la playa "verdegueaban las malvas silvestres"... "Palmeras desmedradas", "toñuces coposos y frágiles" vigilaban de "trecho en trecho las entradas del desierto", y a sus pies ondeaba "la hierba del alacrán, verde y jugosa al nacer, quebradiza en sus mejores días y en la vejez bermeja como sangre de buey". Más allá las palmeras formaban coro y se abría alguna caleta de pescadores, donde se multiplicaban las higueras, ofreciendo sombra a las gentes sencillas. Valdelomar repasa estampas de esas vidas lentas, en que se entrelazan el pescador abuelo que teje las redes con "toscos dedos", "el sorprendido pez", los chiquillos que se "tuestan desnudos al sol", montados sobre "el asno pensativo"; y también los sauces, las gaviotas; naves que se pierden en la neblina con sus gallardos tripulantes; chozas de caña y estera; y en alguna casa del puerto el gallo triunfador "esbelto, magro, musculoso y austero..."

Esos materiales que le ofrece la naturaleza - su universo- hablan de cosas diversas, envuelven signos y símbolos que el poeta siente y desentraña con amoroso arte, que tiene blandura de pan aldeano, vibración de puro dolor y colorido de celajes en bandada sobre el poniente. Dice Valdelomar en una de sus "Neuronas":

"Tiene la naturaleza exaltaciones y depresiones. Tiene la naturaleza instantes de revelación en los cuales se diría que está elocuente. Que habla, que quisiera comunicarse con los hombres. ¿ No habéis sentido alguna vez en el campo, en un momento especial e inexplicable, algo que es como la angustia de lá naturaleza, algo extraño que 
os invita a penetrar en el alma impalpable de las cosas, algo que es como una atracción que ejercen en vosotros fuerzas misteriosas $y$ ocultas? ¿Qué es aquello sino la llamada cariñosa que os hace la madre? ¿No somos por ventura nosotros una parcela de la gran unidad? Creo con toda la fe de que soy dueño, que la naturaleza ha sido, en un principio, una gran unidad armónica y compleja, que perdió su concreción y que trata de volver a ella."

La naturaleza está, pues, diciendo constantemente su "desgarradora verdad".

"A la orilla del mar se piensa siempre -explicaría en uno de sus cuentos-; el continuo ir y venir de las olas; la perenne visión del horizonte, los barcos que cruzan el mar a lo lejos sin que nadie sepa su origen o su rumbo; las neblinas matinales, durante las cuales los buques perdidos pitean clamorosamente, como buscándose unos a otros en la bruma, cual ánimas desconsoladas en un mundo de sombras; las paracas, aquellos vientos que arrojan a la orilla a los frágiles botes y levantan columnas de polvo monstruosas y livianas; el ruido cotidiano del mar, de tan extraños tonos, cambiantes como las horas; y a veces, en la apacible serenidad marina, el surgir de rugidores animales extraños, tritones pujantes, hinchados, de pequeños ojos y viscosa color, cuyos cuerpos chasquean las aguas al cubrirlos desordenadamente..."

El mar está también reflejado en el mensaje que escriben en las tardes los largos cordones de pájaros sobre el cielo; y en las luces que en la noche se extinguen a la distancia "como vidas estériles".

La voz de la costa se escucha en el crecer de los sauces "al borde de la parcela colindante" con el yermo; el sauce "Hebaristo", por ejemplo, está rodeado de "yerbasantas" y "llantenes" y por sus raíces corre "el agua fría y turbia de la acequia". Bajo su sombra medita el hombre, simil en la soledad y en el hastío, en el triste acontecer, en la persecución del amor que no ha de 1legar, en la taciturna actitud de la hora del "toque de ánimas". "La noche envolvía a ambos en el misterio." Los dos "hijos del azar, del capricho y de la sinrazón", esperando inútilmente el florecimiento de las ramas extendidas. Unidos más tarde -hombre y árbol- en la muerte, envuelto uno por el otro, en el inmenso anonimato de la tierra, que sigue prolificando en derredor. El campo es a veces un simple pedazo de jardín. $\mathrm{Y}$ siempre tras el jardín el mar. Por sobre el verde 
de las higueras y el rojo de las corolas, el plomizo humear de las naves manchando el azul del espacio o haciendo resaltar la blancura de las gaviotas, que flotan a sus costados como copos de espuma. En medio de ambos, del campo que es sólo destello, menudo ofrecimiento de la tierra, y del mar que es todo inmensidad, está el jirón de la playa, donde menudean esqueletos de aves, piedras multicolores, yuyos, sombras de náufragos. Allí sobre la playa, el poeta siente venir la muerte:

"E1 divino prodigio del silencio..., el ya callado "rumor de las olas", "la inmovilidad"... "Nada acusaba ya a la Humanidad, ni a la vida. Todo era mudo y muerto. Sólo quedaba el zumbido en mi cerebro, que fué extinguiéndose, hasta que sentí el silencio, claro, instantáneo, preciso..."

La muerte llega con menudos pasos de mujer y con silueta blanca. La muerte ha venido del mar, que él ama tanto; y hacia el mar han de mirar aterrados y fijos "los ojos de Judas", cuya efigie queman implacablemente, todos los años, "los piadosos" aldeanos. Pero también llega "el amor". Ya no es la señora blanca, dulce en la petición del perdón, dramática en la visión postrera: cubierto el rostro con el pelo húmedo y desgreñado; ahora es "Miss Orquídea", pálida niña de "E1 vuelo de los cóndores", con listón negro a la cabeza, con quien cambia sonrisas diariamente, allí, en la orilla. Un día, "Miss Orquídea" se va... Cuando el barco se aleja, sólo queda la confusa visión de un pañuelo "como un ala rota, como una paloma agonizante..." El amor se ha ido sobre el rumor de las aguas y a la tarde aún perdura la cabellera de humo sobre el cielo sangriento del crepúsculo, que forma el leit-motiv de la obra narrativa de Valdelomar.

"Entre las cosas inefables e infinitas que intervienen en el desarrollo de sus leyendas - dice Miriátegui-, con la $\mathrm{Fe}$, el Mar y la Muerte, pone el Crepúsculo. Desde su juventud, su arte estuvo bajo el signo de D'Annunzio. En Italia, el tramonto romano, el atardecer voluptuoso del Janiculum, la vendimia autumnal, Venecia anfibia - marítima y palúdica- exacerbaron en Valdelomar las emociones crepusculantes de $l l$ Fuoco. Pero a Valdelomar -agrega- lo preserva de una excesiva intoxicación decadentista'su vivo y puro lirismo. El humour, esa nota tan frecuente en su arte, por donde se evade del universo d'annunziano." 
Miriátegui expone, respecto a su gracia y su novedosa creación, el anticipo pirandelliano de "Hebaristo, el satıce que murió de amor", que según él, muestra: "el fracaso de una existencia que, en una tentativa superior a su ritmo sórdido, siente romperse su resorte con grotesco y risible traquido".

"Yerbasanta" y "El Hipocampo de Oro" constituyen la alternación de aquellos dos mundos - costa y mar- que se superponen o se enfrentan en Valdelomar, dentro del sentimiento panteísta que ilumina por encima de cualquier nota decadente la obra genial del poeta y del prosador. En una, viven los labradores sobre la eglógica paz de lós campos. Recuerdo de "vendimias", de "tambores de pellejo de cabra", de "azahàres del pacaö", de "la alameda de sauces", del "broquelado pozo". Los niños juegan en los "bosquecillos de toñuces y de pájarobobos". En las noches, el campesino joven, moreno, melancólico, de aldeano amor, canta yaravíes:

En su ventana moría el sol y abajo lento cantaba el mar; y ella reía llena de amor, 'rubia del oro crepuscular...

Murmuran las peras en los árboles lentos y altos y murmuran las olas en la ribera próxima. La tierra húmeda y preñada, el desierto y el mar. Entre un mundo de gorriones, de baldes "de dulce leche con calor de madre", de "uvas pintas", transcurre la nunca descubierta tristeza del mozo chacarero quien, al final de la Semana Santa, se aleja por los últimos retazos de la hacienda, para hundirse definitivamente "en el cerrado misterio tenebroso". Las aguas seguirían debatiẻndose bajo el muelle en "las tinieblas" de cada "noche".

En "El Hipocampo de Oro", de una alada y casi diríamos alegre expresión de cuento infantil, surge en toda su esplendidez el mar. En la orilla asoma la palmera cuya copa semeja "la cabellera de una bruja"; se arrastra "la tortuga obesa", que se despierta al grito de ias gaviotas y saca "la cabeza chata como el índice de un dardo"... "dejando caer dos lágrimas por costumbre más que por dolor"...; y viva Glicina, viuda de algún marino rutilante, blanca "como la leche oleosa de los cocos verdes", y que con ser armoniosa cual "ola antes de reventar", muestra ya una belleza en camino de convertirse en estatua de mármol. El cuento transcurre sobre la playa y tiene 
por personajes centrales al "Hipocampo" - -rey y símbolo del mary a Glicina -espejo de humanidad - en busca del hijo deseado, en persecución de inmortalidad hecha a base de amor y de propio renunciamiento. El océano tiene criaderos de perlas, ejércitos de lacmas, bosques de yuyos, palacios de corales, pero requiere constantemente, para no enceguecer, de nuevos ojos "femeninos", que iluminen las aguas $\sin$ fin, de humana sangre que dé vida a su cuerpo brillante, y del azahar del durazno de los dos almendros que brinde el poder de la sabiduría. $Y$ el mar angustiado vive en acecho de satisfacer sus deseos que a cada vencimiento de luna aparecen nuevamente inalcanzables. Glicina, a su vez, está para ofrecerle ese placer en compensación del hijo que nazca de sus entrañas - carne y hueso o fantasía poética, expresión artística o tosca obra de artesanía. En el trueque de objetos deseados ambos encuentran la satisfacción de sus deseos, pero ya está naciendo, al ras del gozo, un nuevo despertar de angustias por venir o el culumbrarse de la propia muerte. El hombre y el mar están otra vez frente a frente; uno para el otro, uno por el otro. "Todo lo que los hombres anhelan está en el fondo del mar", dice el Hipocampo. Pero a la vez, el hombre viene a traerle, al término del período lunar, los ojos, la sangre y la sabiduría, para que en cambio le dupliquen la porción de "amor". Valdelomar está confrontando siempre a ambos elementos y él asiste diariamente al espectáculo marino. "¿Te gusta mucho el mar?"... preguntará la muerte. Y el poeta, aún niño, dirá en respuesta: "Sí, señora; vengo todas las tardes..."

El drama, como género literario, o sea el dialogar mismo, encontró en "Verdolaga", la superación de otros menores ensayos. Xammar encontró en esta obra un antecedente a ciertos aspectos del moderno teatro lírico y terrígena de García Lorca. Los nombres de los personajes huelen a campo y sugieren bellezas en sí solos. Drama eglógico, tiene por escenario la chacra costeña, y por realización una tragedia de pastores. Membrillejo muere al pie del río; y Espigua, la madre, lo busca por cercos y callejones, por el monte y la arena colindante, y lo halla, al fin, con la cabeza en el agua y el cuerpo sobre la grama, con la herida morada, podrido bajo los rayos del sol fuerte. El campo y el mar hacen también plena aparición. Ellos son los verdaderos personajes detrás de Espigua, Menbrillejo, Damiela, Moscatel, Agüeda, Maura ... Esta última nos ha- 
blará de ellos, pero en verdad son ellos los que hablan por boca de la soñadora:

"La fruta, la jugosa fruta, la alegre fruta. La fruta no está enferma. La fruta no llora, no tiene dolores, no tiene corazón... Los árboles, Agüeda, son buenos; los árboles no dañan. ¿Por qué no te casas con un árbol? Un árbol no te haría sufrir como Claudio. Claudio te amaba y te hacía sufrir. Tú debes casarte con un árbol. Tú eres Agüeda, la señora Durazno."

En cambio:

"El mar... ¿Cómo es el mar?... Mucha agua, agua salada, amarga, agitada. El agua del mar debe ser salada como las lágrimas..."

"Canción primitiva y pastoril" se le ha llamado. Drama de valle costeño y de mar, podríamos añadir que es "Verdolaga", donde los personajes ríen con las flautas de carrizos tiernos y lloran con las viejas cañas que tienen sabor de arena y agua.

Las cosas que lo rodean vibran, en Valdelomar, con la tristeza y la alegría del hombre. Por eso dirá en su "Confiteor":

Mi alma llenará el mundo de alegría, la naturaleza vibrará con el temblor de mi corazón, todos serán felices:

el cielo, el mar, los árboles, el paisaje...

A su conjuro se antropomorfizan océano y costa, pez y árbol, y toman definido carácter. Se hacen personajes que tienen representación viva y la naturaleza se expresa por medio de ellos elocuentemente. Mas no son meros símbolos, pues conservan su función y su papel dentro del universo. El campo destaca bajo el sol ardiente; el mar adquiere su melancólica actitud a la hora "sangrante del crepúsculo". Las aves vuelan como tales al trazar sus signos bajo el cielo, que, a veces, es claramente "abovedado", con "un azul intenso", "como si fuera más grande y más hondo" y los ojos "lo mirarán más profundamente". El desierto "vasto, amarillo, monótono, como otro mar de pena y desolación", se extiende a lo largo de lo que la vista alcanza; y el verde de los árboles del valle estrecho y jugoso, es un manchón de alegría sobre la inmensidad. Es la naturaleza en la tercera etapa del "ritmo". Cada valle costeño 
es un poema que va a morir al mar, levantando al paso imágenes de "yerbasantas", de "sauces", de "verdolagas", de "caballeros carmelos" con bermejas agallas, de "señoras blancas" musitando naufragio en las orillas, de haciendas en vendimia y de procesiones con andas de santo lugareño. Al fondo el océano, donde están varadas las embarcaciones que abandonó el viento y donde lucen los faroles el instante del tramonto; en el interior se agitan los peces entre mundos de líquenes y conchaperlas. E1 hombre es otro poema que se debate entre sus propios desgarramientos y las angustias que le ofrece "su universo". Valdelomar es efectivamente Valle del Mar.

La interpretación del paisaje de la costa peruana constituye seguramente su más preciada veta literaria. Dejemos aparte el fino humor de cuentos yanquis, los intentos de literatura incásica, las manifestaciones periodísticas donde saltaba el "snobismo" a lo Wilde, la exaltación de "nuestro señor yo", que imitaran muchos entre nosotros pero sin la genial llamada a la intimidad, al regolosear de la belleza, que se desprende de la obra de Valdelomar; posición que tiene mucho de revolucionaria contra la mediatización burguesa. Valdelomar no llegó, sin embargo, a la concepción social, a la interpretación de los factores geopolíticos, desde abierto ángulo sociológico. Aunque dijera en alguna de sus "Neuronas": "Sacando a los analfabetos, las gentes del Perú se dividen en dos clases: una que siembra algodón y otra que escribe majaderías" —que representaba una intuitiva crítica del medio-, propiamente no se anticipó a viviseccionar nuestro país con una teoría histórica como tratarían de hacerlo algunos de los que se formaron alrededor suyo en "Colónida". Pero si no percibió, o no quiso expresarlo, el fenómeno social, en cambio dió cabal medida al fenómeno político, proclamando literariamente los altos valores de la nacionalidad: "Invocación a la $\mathrm{Pa}$ tria", "Oración a San Martín" — "desde la tierra fecunda, desde el rincón histórico" - forman parte de su interpretación política y emocional de la realidad circundante. La exaltación de los valores propios no constituyó en él epidérmico y falso chauvinismo. Era la suya, entonación de soñador, pero admonitiva frase patriótica a la vez, buscando, con maestría literaria, el efecto de crear una conciencia nacional dinámica, afińcada en la tierra:

"Vosotros, jóvenes en plena floración de la vida, llenos de ideales, llenos de primavera, ansiosos de laborar por el bien, no 
tenéis Patria todavía... La Patria es orgullo santo, y nosotros no tenemos orgullo. La Patria es haz de voluntades, y nosotros somos abúlicos; la Patria es tea luminosa y radiante, y nosotros estamos en tinieblas; la Patria es fraternidad, concierto de afectos, uniformidad de sentimientos, y nosotros somos desunidos y nos hacemos daño unos a otros..."

Aquí, sí tiende su trayectoria hacia el futuro. $Y$ por eso hoy vuelve a repetir el eco de nuestras piedras lejanas, esta invocación del litoral: "Formad una Patria."

Valdelomar fué, en resumen, admirable intérprete de las voces de la naturaleza con un fino sentido de instrumentación artística que le permitió damos el paisaje de la costa más allá de la copia real, de la simple manifestación eglógica o de la comparación inmediata, pero no tampoco como ropaje inteligente, como delectación de símbolos o de metáforas, sino como intento de dar expresión a la voz misma del universo que estaba hablando para él en cada cosa, en cada animal, en cada accidente natural. La naturaleza era un interminable drama en que sus personajes, obedeciendo a fuerzas misteriosas y ocultas, iban en procura de una definitiva concreción armónica.

Hoy, que la noche tiene una trágica duda, en que vaga en la sombra una pregunta muda; en que se siente que algo siniestro va a venir, que se baña en el pecho la tristeza desnuda, hoy, quisiera morir...

La muerte llega cuando el mar apenas suena sobre la playa desconocida y remota, blanca y solitaria. Playa, el fin humano, de todos modos, aunque en este caso específico se realice el desenlace entre la cordillera, en ciudad de tejados rojos y campanarios de piedra, muy cerca de la pampa donde quedó sellada la libertad de América.

Vendrá la muerte un día, con su hoz encarnada nos tenderá los brazos al fin de la jornada...

Cuando arribó, Valdelomar estaba en Ayacucho, el 2 de noviembre de 1919.

$\mathrm{Y}$ un día seréis seis hermanos, ¡No me olvidéis!... 
Los hermanos literarios de Abraham Valdelomar no to han olvidado, tampoco. Pongo hoy, por eso, sobre su tumba y su recuerdo las simbólicas "flores, albas, secas y finas" de los algodonales.

Augusto Tamayo Vargas, Universidad Nacional de San Marcos, Lima, Perú. 
